\title{
Sustainable Transport Packaging: Evaluation and Feasibility for Different Use Cases
}

\author{
Sarah Pfoser ${ }^{* 1}$, Manuela Brandner ${ }^{1}$, Katharina Herman ${ }^{1}$, Elisabeth Steinbach ${ }^{1}$, Patrick Brandtner ${ }^{1}$ \\ and Oliver Schauer ${ }^{1}$
}

${ }^{1}$ University of Applied Sciences Upper Austria, Roseggerstraße 15, 4600 Wels/Austria; Email: Sarah.Pfoser@fh-steyr.at, Manuela.Brandner@fh-steyr.at, Katharina.Herman@fh-steyr.at, Elisabeth.Steinbach@students.fh-steyr.at,_Patrick.Brandtner@fh-steyr.at, Oliver.Schauer@fhsteyr.at

\section{*Corresponding author: Sarah Pfoser}

Received: 1 April 2021; Revised: 23 April 2021; Accepted: 6 September 2021; Published: 1 November

\begin{abstract}
The continuous increase in e-commerce shipping is causing a critical amount of transport packaging waste. The aim of this paper is a comprehensive presentation of different types of innovations for sustainable transport packaging. Within the paper, classification and evaluation of 37 sustainable packaging solutions are presented, including customized on-demand packaging, alternative materials and closed-loop systems. A multi-criteria evaluation scheme covering a wide range of economic, ecological, operational and social indicators was used to assess the feasibility of the packaging options in different cases. Depending on the degree of innovation and implementation risk, packaging options are proposed as a "Quick Win", "Go Green" or "Thought Leadership" solution. In the conclusion chapter of this paper, recommendations are made for three different use cases, namely grocery, fashion and textiles and electronic goods.
\end{abstract}

Keywords: Packaging, transport, logistics, sustainability

\section{Introduction}

Providers of courier express and parcel (CEP) services are increasingly facing cost pressure, resource scarcity and growing importance of sustainability. Transport packaging largely contributes to logistics costs and sustainability performance. Packaging accounts for 30-35\% of municipal solid waste in industrialized countries [1]. The ever-growing e-commerce volumes cause great variability in freight dimensions and handling requirements. Most often, packaging is not adequately adapted to logistics purposes, causing high inefficiency and wastage. At the same time, customers have developed high level of environmental awareness and demand for green operations [2]. Existing studies on the topic of transport packaging mostly refer to individual packaging approaches and do 
not provide a comprehensive overview of existing solutions. Meherishi et al. [3] compiled a review of literature on sustainable packaging including 59 publications on this topic. The authors show that there are several studies, which compare either packaging design, packaging materials or packaging systems. However, hardly any study conveys a comprehensive overview.

Compared to existing studies, the aim of this paper is to provide a comprehensive overview of current trends and solutions for sustainable transport packaging. The main research question of this study was formulated as follows: What types of innovation currently exist in the area of sustainable transport packaging development, and for which use cases are these innovative packaging solutions feasible? Different options to optimize packaging are mapped and juxtaposed. The feasibility of these options is assessed using a multi-criteria evaluation scheme, thus leading to tangible recommendations for practitioners. The results provide a profound understanding of the opportunities and challenges of different sustainable packaging options. The assessment of transport options is conducted by a multidisciplinary group of experts. The research team evaluating the options involves not only academic staff from different research streams but also industry partners (a CEP provider and a logistics technology provider). The findings help transport managers in choosing an appropriate packaging solution. The remainder of this paper is organized as follows: Chapter 2 describes the methodology and research process of this study. Chapter 3 presents different types of innovations in sustainable transport packaging and thus answers the first part of the research question. Chapter 4 evaluates the sustainable packaging solutions and makes recommendations for three different use cases, thus answering the second part of the research question. Finally, Chapter 5 provides conclusions and an outlook for the future.

\section{Methodology}

A three-step methodological approach (see Fig. 1) was used to obtain a comprehensive overview and examine innovative solutions for sustainable transport packaging. As a first step, extensive desk research was conducted in order to fully cover the variety of technologies and providers existing in the market. Scientific databases (Scopus, Emerald, Ebsco), as well as conventional databases (Google), were used. Keywords used for the search include sustainable packaging, innovative packaging, renewable packaging, circular packaging, reusable packaging, and various combinations of these keywords with other packaging-related terms, such as bags or boxes. Thus, it was possible to compile a list of 37 packaging solutions that might lead to a reduction in greenhouse gas emissions from e-commerce shipments. These 37 packaging solutions were classified into several categories according to their characteristics and features. 


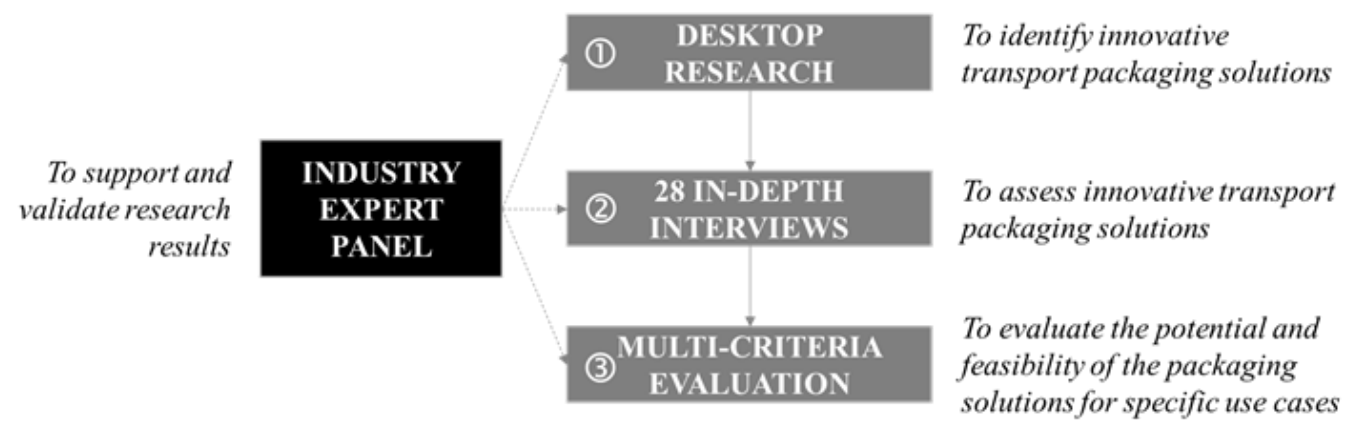

Fig. 1 Research process to study innovative transport packaging solutions. Source: authors

As a second step, in-depth interviews were conducted with providers of the identified innovative packaging solutions. In total, 28 providers agreed to participate in the study. The aim of the interviews, which lasted up to two hours, was to obtain information to assess the packaging solutions and get relevant data for the third step of the research process. This step comprised a multi-criteria evaluation of the 28 packaging solutions with respect to different use cases. A comprehensive evaluation scheme consisting of 33 criteria was used to estimate the potential and feasibility of the packaging solutions (cf. section 4). The whole research process was monitored by an expert panel consisting of eight industry representatives from a large Austrian CEP company and a large Austrian logistics technology provider. This helped classify and evaluate packaging solutions in a practical and relevant way. Bi-weekly meetings with the expert panel ensured continuous involvement.

\section{Innovations for Sustainable Transport Packaging}

Three types of innovation were identified in the context of sustainable packaging. These include i) on-demand innovation, ii) material innovation and iii) closed-loop innovation. In the following subchapter, these three types are discussed and packaging providers with promising solutions are introduced.

\subsection{On-demand Innovation}

On-demand packaging technology is considered a process innovation in the packaging industry and enables the customization of transport packaging to the size of products being shipped. Compared to product innovation, where the customer is usually addressed directly, the customer's interest in the manufacturing process of the packaging is usually lower. However, customers benefit from better quality, increased convenience and lower prices achieved through process innovation [4,5].

The standardization of packaging sizes enables the automation of the handling process. For ondemand packaging machines, packaging dimensions are adjusted 1- or 3-dimensionally. This results in lower transport and protection costs for the goods because no filling material is necessary. Furthermore, economies of scale result in price advantages in the procurement of packaging material. 
Twelve providers of on-demand packaging technology were identified in the survey, out of which nine to be interviewed within this research: Beck Packautomaten, CMC, Kolbus, Packaging by Quadient, Packontime (Kern), Packsize, Panotec, Ranpak, Sealed Air. The majority of the on-demand providers use mainly corrugated boards as production material, followed by paper and plastic foils. Some providers offer both variants. Providers for corrugated boards use the volume optimally and the packages are mainly created in the 3D process. Additional filling material is necessary to a limited extent only, yet Ranpak, for example, additionally offers paper-based filling material. In terms of design options, all providers except $\mathrm{CMC}$ are at the same level, the exception being CMC in this category, as full-color personalization on the packs has been offered by them since 2016. This "PackVertizing" concept enables selling advertising space on the packaging to third-party companies as an additional revenue stream. This eliminates the need to produce pre-printed cartons, which reduces stocks.

In terms of energy consumption, it can be seen that corrugated packaging machines have a higher energy consumption than the polybags packaging machines. Compared to the other providers mentioned above, the machines from Sealed Air have the lowest energy consumption, followed by Beck Packautomaten. Corrugated boards can also be stacked optimally in contrast to polybags and therefore lead in this category.

As for the end of packaging service life, leading companies are Beck Packautomaten and Sealed Air. Beck Packautomaten allows customers to choose between recyclable films, films made from recyclate (plastic that has already been used) or organic films, or films made from renewable raw materials (sugar cane, corn, potatoes). Sealed Air offers LLDPE films in various material thicknesses and designs (recycled, sugarcane molasses), biodegradable films (thistle base) or corrugated boards. Ranpak also offers biodegradable and renewable paper in the category of filling materials. Customers of on-demand machine manufacturers mainly pack general merchandise products, clothing and textiles. These machines are also used by pharmaceutical industry. Grocery and cosmetics sectors use on-demand machines to a limited extent only. For large-scale coverage of the industries, the providers Beck Packautomaten, Ranpak and Sealed Air are recommended, as they already have experience and the required expertise in all areas. Providers that focus on specific products include Kolbus for luxury packaging and Sealed Air for fresh products such as meat and fish and pharmaceutical products. CMC is, above all, a leader in the e-commerce sector and has already won several awards in this industry. Packaging by Quadient is a provider that can optimally compensate for seasonal fluctuations in demand due to the high performance of its machines. 


\subsection{Material Innovation}

Non-renewable resources in e-commerce packaging have been identified as a main cause of environmental problems. Thus, the European Commission has set the goal of decreasing municipal waste by at least $65 \%$. Furthermore, $75 \%$ of packaging waste should be recycled, and the volume of municipal waste in landfills should be reduced by at least 10\% [6]. For that reason, the search for alternative resources has gained interest among scholars. The strategies used for sustainable innovations as such are summarized in the $4 \mathrm{R}$ Strategy developed by the Delft University of Technology, 4R standing for 'recycle', 'reuse', 'renew' and 'rethink'. In this context, recycling means the use of materials used for producing new materials for new packaging; reusing refers to the process of using packaging multiple times; renewing is the use of biodegradable, compostable or renewable materials for packaging; and rethinking is finding new design methods to improve existing packaging solutions socially and environmentally [7]. In the past, researchers proposed new solutions, which consist in using biodegradable, compostable or renewable packaging materials [8,9]. A number of material innovations were presented by Escursell [6] in both primary and secondary packaging.

Paptic [10] is an innovative material made of wood pulp and wood cellulose. The material is completely biodegradable under industrial composting conditions. Due to its technical parameters, resistance and durability, it appears to be applicable for use cases where plastic is usually used. The Paptic material is used to replace plastic bags, polybags and form-fill-seal packaging. The main advantage is that the material can be used with existing packaging machines. Another alternative option is using grass for the production of cartons. This supports the strategy of rethinking packaging by improving its eco-balance. The amount of water needed in the production of grass cartons is as little as 2 liters, compared to up to 60001 used in producing traditional carton. Moreover, life cycle analyses show energy savings of $80 \%$, reduction of $\mathrm{CO} 2$ emissions by $75 \%$ and less use of chemicals in the production process. This is due to the high volume of grass, and therefore, less material is required. Compared to other innovative materials grass carton can influence the odor of the packaging, depending on the amount of grass used. The smell of grass conveys a sustainable and ecofriendly image. The material is used for cartons by Kneipp and Claro and is being tested for OnDemand machines by Ranpak [11].

For temperature-sensitive shipments, there are a number of alternative insulation materials. For example, Temperpack developed ClimaCell, which consists of insulating panels made from corn starch and paper. According to the producer, this allows for $\mathrm{CO} 2$ savings of $65 \%$, compared to a traditional EPS carton. Packit has developed Foodmailer made from corrugated cardboard instead of styrofoam. FSC- certified wood-based raw materials are used for production. Furthermore, paperbased Icepackeco enables keeping perishable food cold. Landbox (from Landpack) is a box made from biomaterials, mainly straw. It can thus be disposed of with organic waste or even in nature. 
Sustainability was also taken into account in the sourcing of the materials as part of the multi-criteria evaluation scheme. The straw in Landpack is straw that would otherwise be considered as waste and therefore, it does not compete with food production. SEAclic produces boxes from bioplastics, made from $80 \%$ bio-based materials. The low weight and very good insulation properties of the product are reminiscent of conventional EPS materials, which, however, are made from non-renewable resources. However, the use of polyacids made from corn is believed to increase food shortages. In addition, EcoCool has developed packaging made from alternative materials. EcoCool uses filling material made from $80 \%$ recycled PET bottles. In the case of packaging for food delivery, rethinking refers not only to the packaging, but also to the functionality of materials when keeping shipped items fresh. Better thermodynamic properties of certain materials are considered as more sustainable. Ecovative used the rethink strategy to change the whole process of producing insulation. The outcome is insulation made from mushrooms instead of styrofoam. The material consists of mushroom mycelium, agricultural waste and hemp shives.

\subsection{Closed-loop Innovation}

The amount of waste generated by linear business models has raised considerable interest in terms of circular solutions. Compared to the linear take-make-dispose approach, circular models allow for maintaining the value of the resources in each cycle by applying strategies such as reuse, refurbishment and recycling [12]. However, the development of closed-loop packaging is still in its infancy. The providers of circular solutions within this research are mainly start-ups, ranging from pilot-phase to more mature start-ups who have already tested their solutions in the first pilot projects. There have been identified thirteen providers of closed-loop innovations (bags and boxes); nine of them agreed to be interviewed within this research: BOOXit, LimeLoop, Livingpackets, Memo, Packoorang, Repack, Returnity, Temprify and xpacksystem. All providers assured that the innovation must not only consist of circular packaging design but above that, it also requires a supporting system, software which shall fulfil a supporting function by tracking parcels and rewarding consumers for returning the packaging. Many providers' offer includes software to be used by the customer as well as an app or a software kit which allows for integrating the end-consumer. Differences can be seen in the protection provided by circular packaging. Some solutions (e.g. Limeloop, Packoorang) provide padding to protect the product from damage during transport. Furthermore, some solutions enable keeping cold or hot temperatures inside the packaging (e.g. Livingpackets or BOOXit). This makes it feasible to transport temperature-controlled goods such as food or drugs with closed-loop packaging solutions.

Multi-criteria evaluation also covers business models and as such, different approaches in the use of business models among the providers interviewed are identified. Repack offers its customers multi- 
use bags in the form of a subscription model and it thus remains the owner of the bags. Other providers sell packaging to their customers and maintenance is ensured through the model of service offering. However, the scope of the service differs among individual providers. While Packoorang includes service throughout the cycle (repair, pick-up, cleaning process, transport to customer), other providers transfer the responsibility of certain cycle steps to the consumer.

\section{Evaluation and Use Cases for Sustainable Transport Packaging}

A multi-criteria evaluation scheme was used to evaluate the feasibility of the identified packaging solutions for different use cases. This evaluation scheme was developed in cooperation with an industry expert panel to ensure that its criteria are relevant in practical handling and operation of transport packaging. The evaluation scheme comprises five categories, each of which contains five to nine evaluation criteria. The first category addresses packaging characteristics ranging from size flexibility, volume fill to visual, sensory and tactile packaging properties. The second category relates to both product and consumer protection and addresses the quality, load-bearing capacity and safety of packaging. The third category considers sustainability and includes factors such as the origin of packaging, reuse and disposal, as well as storage and transportation of packaging. The fourth category focuses mainly on the supplier's business model. Here, a distinction is made between whether ondemand solutions or closed-loop models are involved and if pilot projects are already in progress or if the packaging product is already established on the market. The economic aspects of the solutions (e.g. acquisition and operational costs) constitute the fifth category.

In the evaluation, each criterion was assigned a value between zero and twenty, depending on how much it meets a given criterion. In addition, the evaluation scheme enables weighting individual aspects more or less heavily, as required by the specific use case. Three evaluation classes were used to recommend a suitable packaging solution for i) grocery, ii) fashion and textiles and iii) electronic goods use cases. These three evaluation classes are as follows: 1) Quick Win (best cost-benefit ratio, fast to implement, (comparably) low implementation risk and a low degree of innovation), 2) Go Green (high positive environmental effects, longer preparation and implementation time required, medium implementation risk) and 3) Thought Leadership (a very high degree of innovation, high implementation risk and costs, longer-term projects). For each use case (food, fashion and textiles, electronic products), a "winner" was determined in the evaluation classes, whose solution best meets the objectives according to the evaluation.

\subsection{Use Case "Grocery"}

Food transport is subject to legal requirements, which are regulated within the European and national legislation. Regulation EC No. 178/2002 ensures due diligence and traceability of foodstuff. Due 
diligence refers to the integrity of the food and traceability must be possible back to the origin of the goods in all production stages. Compliance with health and temperature requirements is specified in the regulation EC no. 852/2004. This relates to compliance with HACCP guidelines and prevents contamination of food and interruption of cold chain [13]. Two companies were identified as winners in the grocery use case: The EcoCool Smartliner as a Quick Win solution and Ranpak as a Go Green solution (see Fig. 2). With a high insulation performance and a temperature guarantee of 45-53 hours, Smartliner stands out among the suppliers. Only Landpack's Landbox offers better insulation performance, although it is also more expensive. Other benefits of the EcoCool Smartliner include low investment costs and process changeovers.

Ranpak is seen as the optimal Go Green solution. This is because two environmental benefits can be achieved by using the machines. First, empty space of the packaging is reduced to minimum and second, environmentally-friendly, alternative material is used for the insulation. An alternative solution is Smartcooler by EcoCool used in combination with a Ranpak machine. Smartcooler, made from $80 \%$ recycled PET bottles, shows the same advantages as Smartliner; it is very light, and has a small footprint at low cost. Combined use of Smartcooler with a Ranpak machine, which produces filling materials, provide additional environmental benefits.

The concept of BOOXit evolved as a Thought Leadership solution (see Fig. 2). BOOXit offers a high degree of automation and thus a high potential for the use within an Industry 4.0 system. The CP (Communication \& Presentation) level for classifying the communication and identification capability of BOOXit boxes is CP33, which means it is an individually known active communication capable component. To exploit its full potential, pick-up stations and the willingness of partners to bear the high investment costs of the BOOXit system are necessary, as currently only 3D-printed models of the box are available and a production start depends on finding investors.

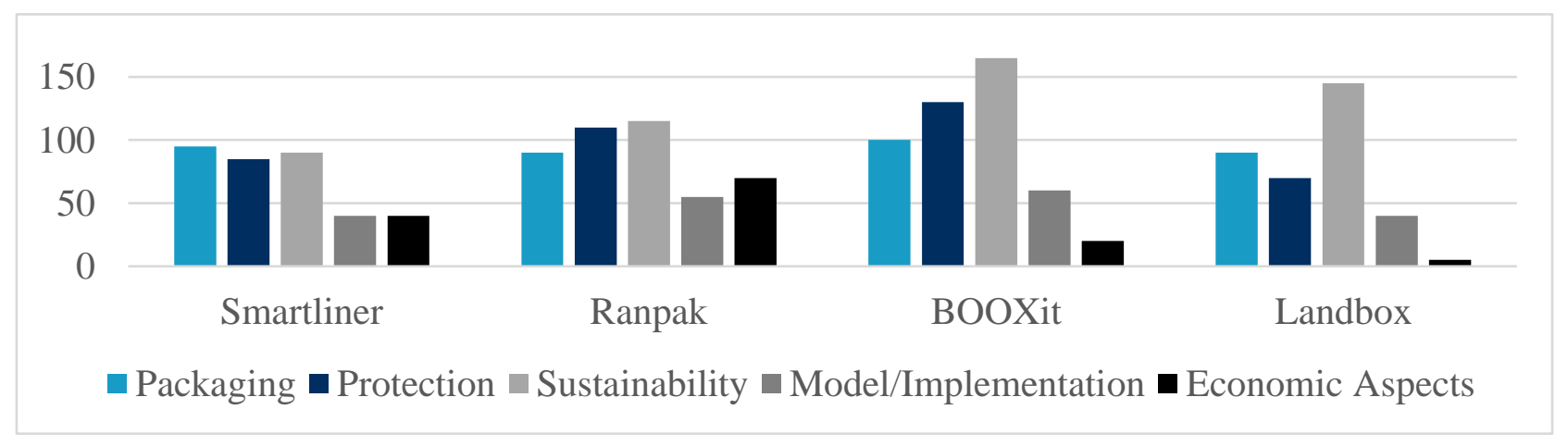

Fig. 2 Winners in the category "grocery". Source: authors

\subsection{Use Case "Fashion and Textiles"}

A review of packaging in the fashion industry shows the dominance of polybags used for packaging of garments. Polybags are primarily made from LDPE; however, individual brands choose alternative 
materials such as bio-based LDPE, compostable plastic blends, paper and polyvinyl alcohol. The identified Quick-Win solution in the fashion sector is from Beck Packautomaten, an on-demand packaging machine (see Fig. 3). The machines are energy-saving and cost-effective compared to other providers and produce both paper bags and polybags. The company differs from its competitors by offering various types of closures such as tear-open strips, tear-open perforation, carry handle packaging as well as resealable bags.

The multi-use plastic bag Packoorang is suggested as a Go Green Solution (see Fig. 3Compared to other solutions, it shows the highest positive environmental effects. A Life Cycle Analysis from a third party [14] presents positive results in terms of the environmental impact of multi-use bags produced by Packoorang. This enables $81 \%$ reduction of $\mathrm{CO} 2$ emissions for a single-use of this solution, compared to a NO6. cardboard box carton. For the multi-use, results of cradle-to-cradle analysis show the reduction of CO2 emissions of 19.35t in the shipment of 100k products (compared to carton). No comparison with polybags was provided; however, lower emissions are assumed when comparing Packoorang with polybags. Packoorang is still in a start-up phase, which was identified as a potential risk. Little is known about the alignment of stakeholders for a functioning business model. Furthermore, an infrastructure is needed to allow for a functioning return process.

The concept of BOOXit again emerged as a Thought Leadership solution for the fashion use case (see Fig. 3). BOOXit involves a concept of pickup points where several boxes are in a locker. This could be especially profitable in view of the high return ratio for online clothing. The u empty space is better exploited in return trips due to the direct collection of return shipments.

If items such as sporting goods are subject to seasonal fluctuations, or if there is a desire for a rental model, packaging by Quadient machine is recommended (see Fig. 3). These machines produce up to 1,100 packages per hour and can be rented for 3, 5 or 7 years.

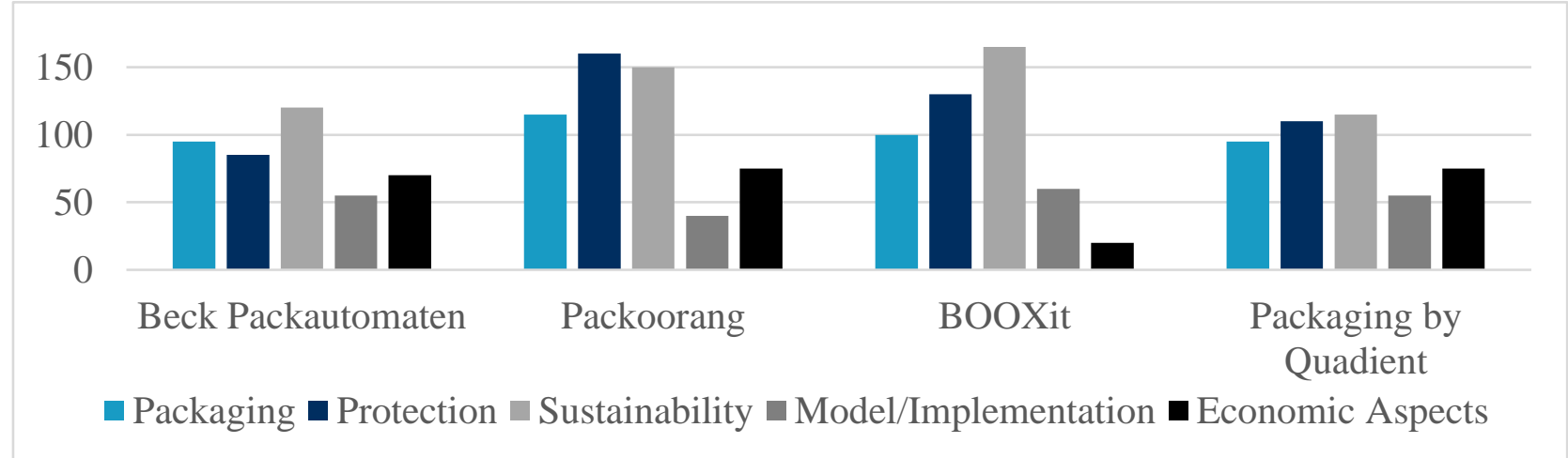

Fig. 3 Winners in the category "fashion and textiles". Source: authors

\subsection{Use Case "Electronic Goods"}

The main objective of electronic goods packaging is to protect them from physical (mechanical and weather), chemical and biological damage. The design of the packaging should fully protect the goods 
during the transportation. Packaging accessories, such as insulated gaskets and pads, should protect the goods from shock, vibration, and collision. However, the most common gaskets are made of solid or corrugated cardboard, and most shock anti-shock pads of foamed plastic (polystyrene, polypropylene), blister film, paper strips, lignin, etc. To ensure adequate safety of the goods, the packaging must have a suitable closure. This means that the packaging must be tight and durable, and the handling of both opening and closing must be easy. Especially if the customer wants to return the product, a reclosure is important [15]. Additional features such as IoT enable tracking of goods (e.g. location systems for object search) and detecting their condition (e.g. temperature, physical properties). In addition, the presence of certain objects or people (e.g. children) in the room can be detected by IoT sensors and possible dangers indicated [16].

Quick-Win solution in this sector are CMC's on-demand packaging machines (see Fig. 4). With customers such Walmart or Zalando, CMC is not only the leader therein but also shows a high level of automation of the machines with a production of 1,000 packages per hour.

The Packoorang multi-use bag is again identified as a Go Green solution (see Fig. 4). Due to the optional padding, the solution provides sufficient protection for the basic use case. The responsibility of the material flowing in the cycle remains with Packoorang. Thus, Packoorang is rated higher in the category of "implementation". The multi-use box of Livingpackets is suggested as a Thought Leadership solution due to the high degree of innovation but also higher implementation risk (see Fig. 4), enabling the tracking of goods, detecting the condition of goods (e.g. impact, humidity, temperature) by using sensors and geofencing. Their packaging is reusable and filling material is not necessary. With $40 € /$ month/box, the rental costs are high and therefore, Livingpackets specializes in the transport of expensive and fragile goods such as electronics. The first pilot project is scheduled for early 2021 in France.

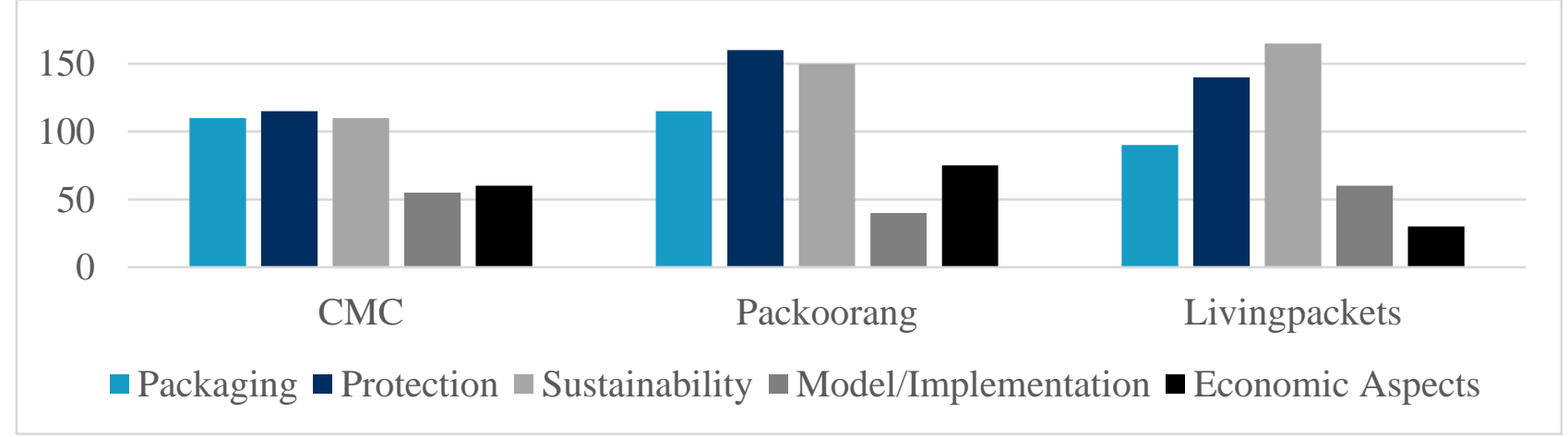

Fig. 4 Winners in the category "electronics goods". Source: authors

\section{Conclusion and Outlook for the Future}

The main task of packaging is to protect the goods being distributed. Previous research highlights the importance of this factor not only when the goods are shipped to the consumer but also when goods are returned. Therefore, packaging must provide enough protection to return the goods back to the 
retailer without being damaged. In order to ensure a positive customer experience, researchers have further identified the importance of labelling on packaging. Additionally, experts emphasize the flexibility of packaging, which allows to save filling [17]. As can be seen above, transport packaging has a lot of functions and requirements to fulfill. In this paper, innovative and sustainable packaging solutions were investigated and analyzed with regard to meet various transport-packaging requirements. Three main types of innovation for sustainable packaging were identified: i) ondemand, ii) material and iii) closed-loop innovations.

While on-demand packaging solutions and alternative materials can be seen as technological innovation, closed-loop solutions are considered as a process innovation. Through automated process operations of packaging with the on-demand packaging machines, corrugated boards or plastic films are adjusted to the cargo content and reduces the packaging waste by about 30 percent. Alternative materials refer to packaging that is either biodegradable, compostable or renewable. A possible approach would be to combine alternative materials with an on-demand packaging machine to achieve the best possible outcome. Some providers have already started testing alternative materials. In contrast, reusable packaging is seen as a closed-loop innovation. However, the development of closed-loop packaging is still in its early stages. The providers of closed-loop solutions within the scope of this study are mainly start-ups that are in the pilot or testing phase.

The feasibility of the identified packaging solutions was evaluated using a multi-criteria evaluation scheme developed in cooperation with an industry expert group. Recommendations for a sustainable packaging solution were made for the following use cases: grocery, fashion and textiles, electronics. Using the evaluation classes of Quick Win, Go Green and Thought Leadership, the winners as well as alternative packaging solutions for special requirements (e.g. seasonal fluctuations, particularly high temperature guarantee) were determined.

Suggestions for further research include a survey of consumers' acceptance of sustainable transport packaging. There is undoubtedly a high demand for sustainable products, but the question remains whether consumers are also interested in sustainable packaging, and especially whether they are willing to pay for it. Using appropriate communication to promote sustainable packaging and offering appropriate pricing models can facilitate the implementation of the identified sustainable transport packaging solutions. This will ensure that sustainable packaging is accepted by the market and will succeed in gaining the required environmental benefits.

\section{References}

[1] Tencati, A., Pogutz, S., Moda, B., Brambilla, M. \& Cacia, C. (2016). Prevention policies addressing packaging and packaging waste: Some emerging trends. Waste Management 56, 35-45. DOI: 10.1016/j.wasman.2016.06.025. 
[2] De Jaeger, S. \& Rogge, N. (2014). Cost-efficiency in packaging waste management: The case of Belgium. Resources, Conservation and Recycling 85, 106-115. DOI: 10.1016/j.resconrec.2013.08.006.

[3] Meherishi, L., Narayana, S.A. \& Ranjani, K.S. (2019). Sustainable packaging for supply chain management in the circular economy: A review. Journal of Cleaner Production 237, 117582. DOI: 10.1016/j.jclepro.2019.07.057.

[4] Franken, R. \& Franken, S. (2011). Integrated knowledge and innovation management. With case studies and examples from company practice (in German). 1st edition Wiesbaden: Gabler.

[5] Disselkamp, M. (2012). Types of innovations. In Disselkamp, Marcus (Ed.), Innovation Management (in German) (pp. 21-30). Wiesbaden: Springer Fachmedien.

[6] Esurrsell, S., Llorach-Massana, P. \& Roncero M. Blanca (2021). Sustainability in e-commerce packaging: A review. Journal of Cleaner Production 280, DOI: 10.1016/j.jclepro.2020.124314.

[7] Coelho, P.M., Corona, B., Klooster, R. \& Worrell, E. (2020). Sustainability of reusable packaging-Current situation and trends. Ressources, Conservation \& Recycling 6. DOI: 10.1016/j.rcrx.2020.100037.

[8] Licciardello, F. (2017). Packaging, blessing in disguise. review on its diverse contribution to food sustainability. Trends in Food Science \& Technology 65, 32-39. DOI: 10.1016/j.tifs.2017.05.003.

[9] Narayanan, M., Loganathan, S., Valapa, R.B., Thomas, S. \& Varghese, T.O. (2017). UV protective poly(lactic acid)/rosin films for sustainable packaging. International Journal of Biological Macromolecules 99, 37-45. DOI: 10.1016/j.ijbiomac.2017.01.152.

[10] Paptic (n.d.). (2021). Paptic.com. With assistance of Paptic. Edited by Paptic. Retrieved March 24, 2021, from https://paptic.com/

[11] Egger, J. (2021). Grass paper packaging (in German). With assistance of Egger. Edited by $\begin{array}{lllll}\text { Egger. } & \text { Retrieved 24, } & \text { 2021, from }\end{array}$ https://www.eggerdruck.de/graspapierverpackungen.html

[12] Peck, P., Richter, J.L., Dalhammar, C., Peck, D., Orlov, D., Machacek, E. \& Voytenko Palgan, Y. (2019). A compendium by the International Institute for Industrial Environmental Economics (IIIEE) at Lund University. Retrieved March 17, 2021, from https://lup.lub.lu.se/search/ws/files/96022489/Circular_Economy_accessibility_compressed.p df

[13] Michel, V. \& Siegfried, P. (2021). Digitale Speditionen in der Lebensmittellogistik - Digital freight forwarders in food logistics. Logistics Journal: Logistics Journal : referierte Veröffentlichungen. 2021 (02), DOI: 10.2195/lj_NotRev_michel_de_202102_01.

[14] Larsen, J., Moxness, T. (2021) Environmental report (in Swedish). Packoorang AS. With assistance of Joakim Larsen, Thomas Moxness. Edited by Logisticrådgivning.

[15] Korzeniowski, A. \& Jasiczak, J. (2005). Accomplishment of selected package functions in ecommerce. LogForum 1 (1,2). Retrieved March 17, 2021, from LogForum http://www.logforum.net/vol1/issue1/no2/

[16] Alioto, Massimo (2017). Enabling the Internet of Things. Cham: Springer International Publishing.

[17] Freichel, S., Wollenburg, J. \& Wörtge J. (2020). The role of packaging in omni-channel fashion retail supply chains- How can packaging contribute to logistics efficiency?. Logistics Research 13 (1), DOI: 10.23773/2020_1. 